\title{
The use of lighting simulation in the evidence-based design process: A case study approach using visual comfort analysis in offices
}

\author{
Anahita Davoodi ( $\varangle)$, Peter Johansson, Myriam Aries \\ Department of Construction Engineering and Lighting Science, Jönköping University, Sweden
}

\begin{abstract}
The EBD-SIM (evidence-based design, simulation) framework is a conceptual framework developed to integrate the use of lighting simulation in the EBD process to provide a holistic performance evaluation method. A real-time case study, executed in a fully operational office building, is used to demonstrate the framework's performance. The case study focused on visual comfort analysis. The objective is to demonstrate the applicability of the developed EBD-SIM framework using correlations between current visual comfort metrics and actual human perception as evaluation criteria. The data were collected via simulation for visual comfort analysis and via questionnaires for instantaneous and annual visual comfort perception. The study showed that for user perception, the most crucial factor for visual comfort is the amount of light on a task area, and simple metrics such as $E_{\text {h-room }}$ and $E_{\text {h-task }}$ had a higher correlation with perceived visual comfort than complex performance metrics such as Daylight Autonomy (DA). To improve the design process, the study suggests that, among other things, post-occupancy evaluations (POEs) should be conducted more frequently to obtain better insight into user perception of daylight and subsequently use new evidence to further improve the design of the EBD-SIM model.
\end{abstract}

\author{
Keywords \\ building performance simulation, \\ lighting simulation, \\ lighting quality, \\ visual comfort, \\ office field study, \\ evidence-based design
}

\section{Article History}

Received: 4 March 2019

Revised: 21 August 2019

Accepted: 27 August 2019

(c) The Author(s) 2019.

\section{Introduction}

Lighting simulation tools help designers analyze different aspects of lighting quality in lit environments and assess alternative design solutions (Reinhart and Fitz 2006) that provide an opportunity to improve the quality of lighting. The applications and functions of these tools are growing rapidly, and lighting designers, engineers, and architects increasingly tend to use them (Hien et al. 2000; Reinhart and Fitz 2006). The nature of light, which is a constituent of the physical system, is understood relatively well, which makes it possible to express it in mathematical terms. To gain the advantages of lighting simulation tools, it is important to have a good awareness of the correlation between the tools' performance metrics and human perception (Cuttle 2015; Davoodi 2016). It is also important to have a good understanding of human needs and preferences as well as how they can be translated into calculable metrics.

Evidence-based design (EBD) provides a systematic process to achieve this goal by providing a process to compile and aggregate the knowledge based on evidence from various sources and present it in a way that would make it easier to apply the knowledge by practitioners (Vischer and Zeisel 2008; Vischer 2009). The EBD process, as defined by the Center for Health Design (CHD), includes the following eight steps: (1) Defining evidence-based goals and objectives; (2) Finding sources for relevant evidence; (3) Critically interpreting relevant evidence; (4) Creating and innovating evidence-based design concepts; (5) Developing a hypothesis; (6) Collecting baseline performance measures; (7) Monitoring implementation of design and construction; and (8) Measuring post occupancy performance results (Malone et al. 2008).

The EBD-SIM framework (Davoodi et al. 2017) is a conceptual framework developed to integrate the use of lighting simulation within the EBD process. In the development of this framework, it was indicated that EBD process steps $4,6,7$, and 8 are the steps where lighting simulation can be integrated into the design cycle. The study concluded that the translation between the user evaluation and the simulated evaluation was a critical step in the 
integration of lighting simulation with EBD. Therefore, the post-occupancy evaluation (POE), step 8 , was chosen as the main subject in the current study. To explain the application of the EBD-SIM framework in a POE step, a study was conducted to analyze visual comfort from subjective ('the user') and objective ('the simulation') points of view. The two research questions are as follows:

1) How are the most frequently used visual comfort metrics correlated with perceived occupant visual comfort? and

2) To what extent are instantaneous and annual human visual comfort perception correlated with simulated comfort assessment?

\subsection{Literature review of the field of visual comfort}

There is a growing body of research in the field of visual comfort. This can range from improvement in visual comfort (i.e., Michael et al. 2018) to optimization of it in relation to other parameters (i.e., Vassiliades et al. 2018), as well as assessment (i.e., Kent et al. 2019a), evaluation (i.e., Kent et al. 2019b), or prediction of visual comfort (i.e., Jakubiec et al. 2015). A wide range of methods are applied in this field, such as qualitative, quantitative and mixed methods. Here, the focus of the literature review is on identifying the available performance metrics that are used for evaluation of visual comfort as well as subjective-objective evaluation of visual comfort by means of simulation tools.

Several studies have identified the lighting factors that affect human visual comfort. Ruck et al. (2000) identified four primary performance factors related to visual comfort: illuminance, glare, distribution, and direction. In a similar study, Carlucci et al. (2015) reviewed the available performance metrics related to visual comfort, listed 34 indices used in this field and categorized them into four groups: (1) the quantity of light, (2) the distribution of light, (3) glare, and (4) the quality of light in rendering colors. Van Den Wymelenberg (2013) argued that due to its ease of use and low cost to measure, horizontal illuminance was the most widely used metric. Advances in the computational power of daylight simulation allowed the calculation of more complex performance metrics, such as dynamic climatebased daylighting metrics (e.g., Daylight Autonomy, spatial DA, and Useful Daylight Illuminance) and metrics related to glare analysis, including Daylight Glare Probability (DGP) and Annual Sunlight Exposure (ASE) (Nabil and Mardaljevic 2006; Reinhart et al. 2006; Wienold and Christoffersen 2006; Heschong et al. 2012). In a study conducted by Jakubiec et al. (2015), simulation tools were used for the prediction of occupants' visual comfort within daylit environments. The results illustrate that it is possible to use current simulation-based visual comfort predictions to predict occupants' long-term visual comfort assessments in a complex daylit space. Subjective-objective evaluation of visual comfort metrics conducted by Bian and Luo (2017) showed that simple luminance metrics (e.g., work plane luminance and vertical eye illuminance) outperformed complex glare indices (e.g., DGP/DGI and luminance ratio). Vertical illuminance had the highest degree of correlation with user visual comfort in a study by Van Den Wymelenberg and Inanici (2014). Visual comfort in typical classrooms of educational buildings in Cyprus was studied through multiple methods, including a field study using a questionnaire-based survey, as well as through static and dynamic simulations and in situ lighting measurements (Michael and Heracleous 2017). The results showed that the amount of daylight was sufficient throughout a year, but excessive glare prevented proper utilization of daylight. The study proposed different strategies based on the room orientation to deal with glare to improve visual comfort and optimize natural lighting performance.

\section{Methodology}

\subsection{Research design}

A study in a fully operational office building, focusing on visual comfort analysis, was conducted to explain the application of the EBD-SIM framework in the POE step. In the first step of EBD-SIM, 'visual comfort' is defined as a value of interest. Then, steps 2-6 of EBD were performed to identify the performance metrics and questionnaire items related to the evaluation of visual comfort from objective and subjective points of view and to develop a hypothesis for testing the validity of the results. These steps were performed in a prestudy and are presented in a dashed circle. In step 8, which is the focus of this study, objective data of the built environment were collected via computational modeling, and subjective data were collected using an online questionnaire (see Fig. 1).

\subsection{Procedure}

First, the physical environment was modeled, and performance metrics were calculated. The simulation results were compared against a limited and random set of illuminance measurements in the real building to check if they were in the same range. Second, using an online questionnaire, occupant characteristics were recorded, and their feedback regarding visual comfort was gathered. Finally, the user feedback and simulation output were compared. This comparison was made to investigate how metrics measured by simulation tools (to assess visual comfort) correlate with actual visual comfort perceived by users and to answer the two research questions and evaluate two hypotheses (see Fig. 1). 


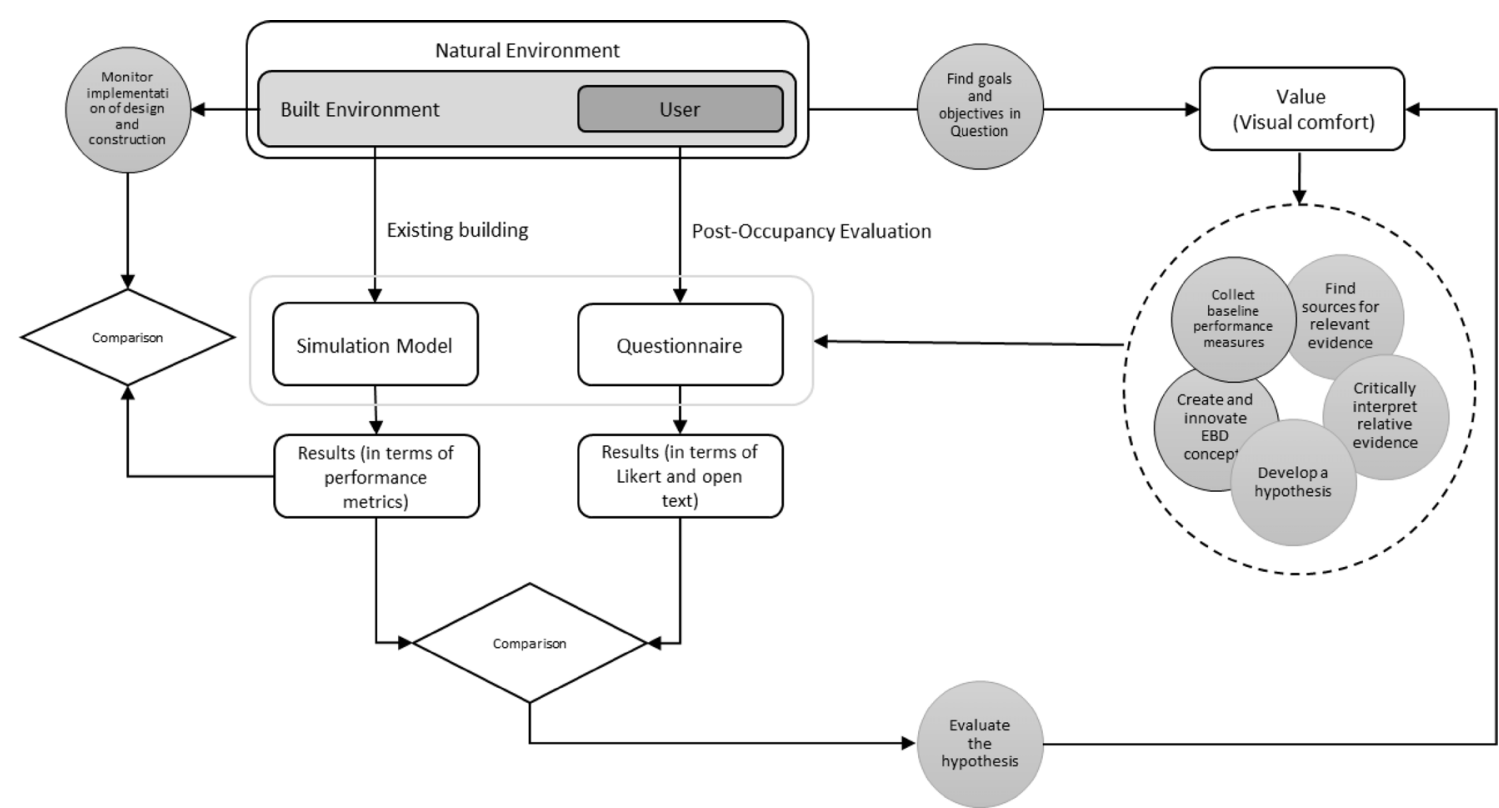

Fig. 1 The EBD-SIM theoretical model addressing the workflow during the post-occupancy evaluation step when implementing computational modelling

The study covered both long-term and short-term evaluations of the lit environment. This means that the 'questions' and 'performance metrics' take into account both instantaneous situations and the annual situation of the lit environment.

\subsection{Site}

The study was carried out in a four-story academic building (with a basement) located in Jönköping, Sweden (lat. $57.778168^{\circ} \mathrm{N}$, long. $14.163526^{\circ} \mathrm{E}$ ). One of the wings of this building was selected for the study, and this wing and its direct surroundings were modeled (see Fig. 2). Data were collected from 15 private office rooms on the second floor (5 rooms) and third floor (10 rooms) of the building (see Fig. 3) during the fall under clear, cloudy and overcast sky conditions to cover the minimum to maximum range of possible daylight with and without direct sunlight to which the participants were exposed when they were answering the questionnaire. The rooms are approximately $10 \mathrm{~m}^{2}$ and are furnished mainly by a large desk, a chair and one or more bookshelves. The rooms have windows on either the north-east or south-west sides. The size of the windows on the third floor is $4 \mathrm{~m}^{2}$, which is one-third smaller than those on the second floor $\left(6 \mathrm{~m}^{2}\right)$. Rooms were categorized into four groups based on their orientation and floor level. L2 and L3 represent the second and third floors, and $\mathrm{N}$ and $S$ represent the north-east and south-west locations, respectively. There is permanent solar shading at the building's south and south-west sides (see Fig. 2). All rooms are equipped with conventional suspended luminaires that were used

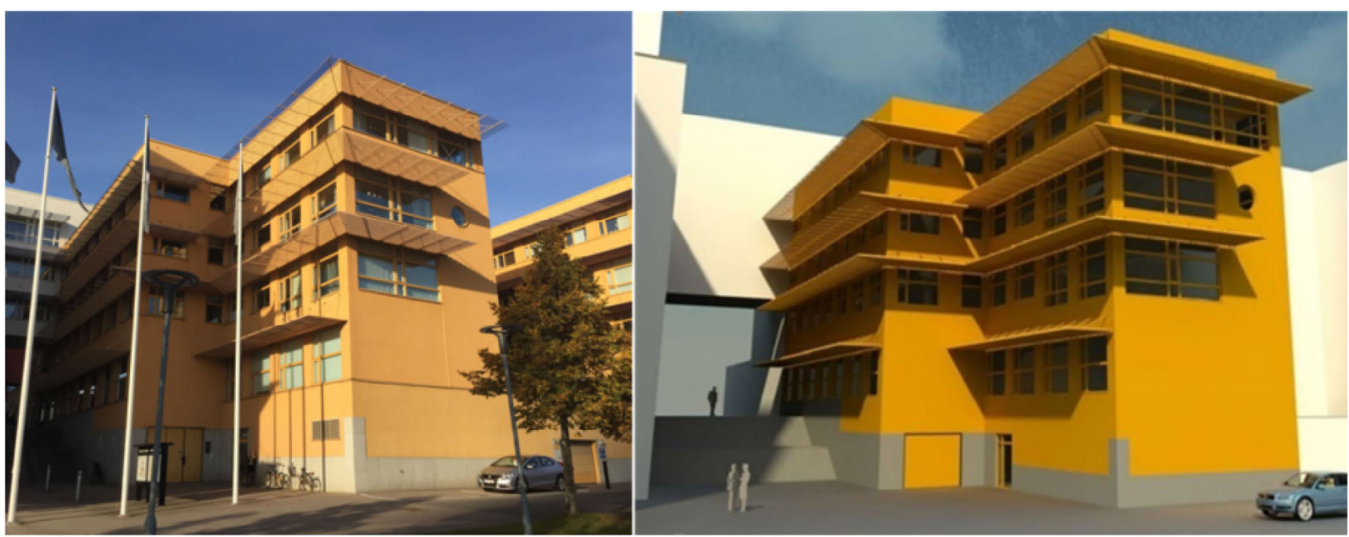

Fig. 2 Photo of the real building (left) and a 3D render of the building model (right) showing the South and South-West facade including the permanent overhang (note that on this side of the building the basement level is above the ground) 


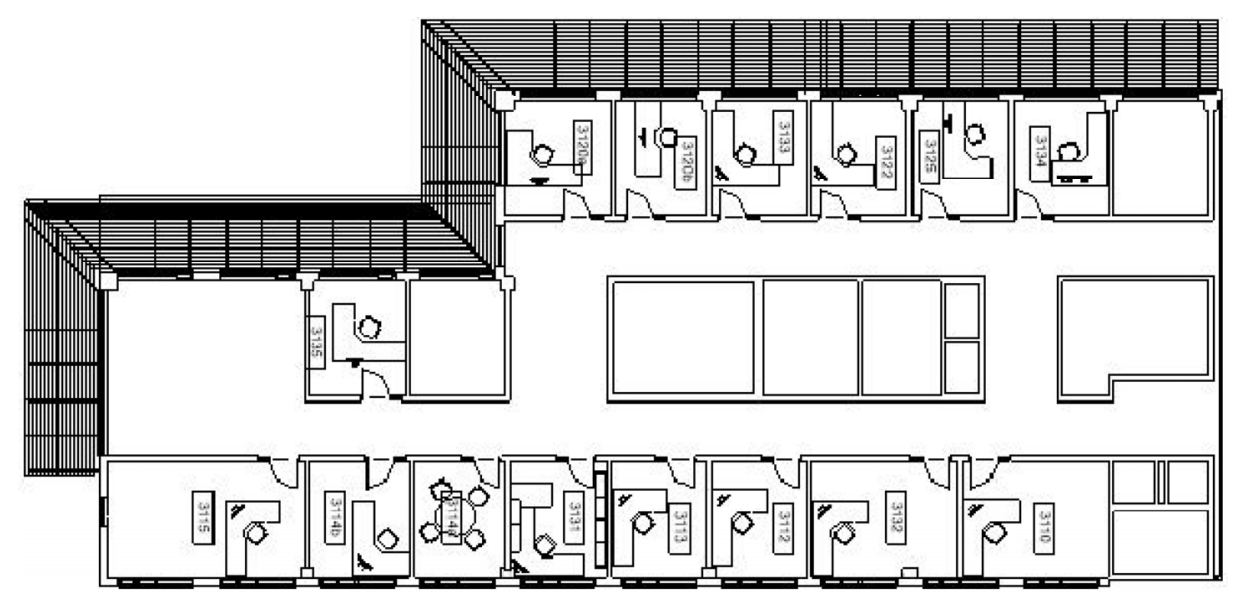

Fig. 3 Floor plan of the third floor of the studied building

according to the users' needs during the survey, but they were not modeled.

\subsection{Survey participants}

The occupants of the second and third floors of the building were invited to participate in the survey. They were academic employees whose work involves research and teaching/ education, mostly using computers. The invitation email was sent to 24 people, 17 of whom responded to the survey (response rate $71 \%$ ). Two of them were excluded from the survey because they were using their rooms for only a limited period. Participants responded to questionnaires at the beginning of October, all within one week with variable daylight conditions. In total, 15 people ( 9 male / 6 female, average age $47 \pm 10$ years) participated in the study, and 12 people had worked for more than two years in their current office room. Most participants $(N=11)$ reported 'wearing vision aids' such as wearing glasses or contact lenses (near vision $=3$, distance vision $=3$, and both $=5$ ).

\subsection{Performance metrics for visual comfort}

Based on literature findings (Appendix 1A), seven performance metrics for visual comfort assessment in a daylit situation were selected (see Table 1).

For instantaneous situations ('moment in time'), gridbased horizontal illuminance calculation was selected to calculate the amount of light on the task area (workplace) and office space. Mean, maximum and minimum values of the sensor points were calculated for further analysis. Vertical eye illuminance $\left(E_{\mathrm{v} \text {-ye }}\right)$ and Daylight Glare Probability (DGP) values were calculated in the center point of each room. DGP was selected since it yields the most acceptable result to predict the occurrence of discomfort glare for daylighting analysis (Jakubiec and Reinhart 2012).
Table 1 Collected visual comfort metrics (daylighting)

\begin{tabular}{|c|c|c|}
\hline Criteria & Metrics & Time \\
\hline \multirow{7}{*}{$\begin{array}{l}\text { Illuminance (under } \\
\text { CIE Standard Clear } \\
\text { Sky, CIE Intermediate } \\
\text { Sky and CIE Standard } \\
\text { Overcast Sky) }\end{array}$} & Max/min illuminance-Task $\left(E_{\mathrm{h} \text {-task }}\right)$ & Moment \\
\hline & $\operatorname{Max} /$ min illuminance-Room $\left(E_{\mathrm{h} \text {-room }}\right)$ & Momen \\
\hline & Average illuminance-Task $\left(E_{\mathrm{h} \text {-task }}\right)$ & Moment \\
\hline & Average illuminance-Room (Eh-room $)$ & Momen \\
\hline & Vertical eye illuminance $\left(E_{\mathrm{v} \text {-eye }}\right)$ & Momen \\
\hline & Daylight Autonomy (DA) & Annual \\
\hline & Spatial Daylight Autonomy $(s D A)$ & Annual \\
\hline $\begin{array}{l}\text { Glare (under CIE } \\
\text { Standard Clear Sky, }\end{array}$ & Daylight Glare Probability (DGP) & Momen \\
\hline $\begin{array}{l}\text { CIE Intermediate Sky } \\
\text { and CIE Standard } \\
\text { Overcast Sky) }\end{array}$ & Annual Sunlight Exposure (ASE) & Annual \\
\hline
\end{tabular}

For the annual situation of horizontal illuminance, the Daylight Autonomy (DA) metric was selected. Additionally, Spatial Daylight Autonomy (sDA) and Annual Sunlight Exposure (ASE) were selected since they have been approved by IESNA as performance metrics in this field (Heschong et al. 2012).

\subsection{Simulation model}

The building was modeled in Autodesk Revit. For detailed daylight analysis, the model was exported to Rhinoceros 3D to perform lighting analysis with the DIVA plugin. DIVA is an environmental analysis plugin that enables lighting performance evaluation employing validated simulation tools, including Radiance and Daysim (Jakubiec and Reinhart 2011). In addition to the simulated building wing, the direct surroundings were also modeled to take potential shading into consideration. The material properties and simulation parameters used for the calculations are described in Table 2. 
Table 2 Material properties and simulation parameters

\begin{tabular}{ll}
\hline Material & Reflectance / visible light transmittance (Tvis) in \% \\
\hline Walls & White interior wall 70\% \\
Floor & Generic floor 20\% \\
Ceiling & Generic ceiling 70\% \\
Desk & Generic furniture 50\% \\
Glazing & Glazing double pan 80\% \\
External shading & Metal sheet \\
Surrounding building & Outside faced 35\% \\
Ground & Outside ground 20\% \\
\hline \multicolumn{2}{c}{ Simulation parameters for daylight autonomy } \\
\hline Weather data & Goteborg - Landvetter Airport, Sweden \\
Occupancy schedule & 8-18 with Daylight Saving Time (DST) 60 min \\
Target illuminance & 300 lux \\
Radiance parameters & -ab2 -ad 1000 -as 20 -ar 300 -aa \\
Sensors density & Grade sensor - 750 mm above 450 mm distance \\
Shading & No automated shading \\
Electric lighting & No electric lighting \\
\hline
\end{tabular}

For each workplace area on the second and third floors, a grid of $0.45 \mathrm{~m} \times 0.45 \mathrm{~m}$ at workplace height $(h=0.75 \mathrm{~m})$ was used to calculate the mean, minimum and maximum horizontal illuminance under CIE Standard Clear Sky, CIE Intermediate Sky and CIE Standard Overcast Sky conditions (for the rest of this paper, these skies are referred to as 'clear', 'intermediate' and 'overcast' sky conditions, respectively). The same settings were applied for the room area of each room for horizontal illuminance $\left(E_{\mathrm{h} \text {-room }}\right), \mathrm{ASE}$, and DA calculations. The point in the middle of each room with a direction toward the windows was selected for vertical eye illuminance $\left(E_{\mathrm{v} \text {-eye }}\right)$ and DGP calculations under clear, intermediate, and overcast sky conditions.

The questionnaire was filled out in early October, and therefore, for the simulation, a day in early October (11th) was chosen to obtain a comparable day length and sun path. In total, $60 \%$ of the questionnaires were filled out in the morning; hence, for the simulation, a time in the morning was selected (10 AM).

\subsection{Questionnaire}

The questionnaire was a web-based form in English to collect feedback regarding the visual comfort perception of office occupants. It contained questions from various questionnaires (Hygge and Lofberg 1997; Veitch et al. 2007; Bluyssen et al. 2011) and was intended to be completed in 10-15 minutes (Appendix 1B). After introducing the survey and its purpose, questions were asked regarding office characteristics, satisfaction with the lit environment in general ('annual'), satisfaction with the lit environment at the time of response ('momentary'), user preferences and behavior regarding light and space use, as well as personal information. Multiple questions inquired for the same aspect but asked the participant to answer for a situation with 'only daylight' or 'only electric lighting'. In total, 46 questions were asked, of which 17 questions were multiple choice, three questions were multiple-choice grid, seven questions were open-ended questions, one question was checkbox selection and all other questions used a 7-point Likert satisfaction scale $(1=$ very satisfactory to $7=$ very unsatisfactory). For the analysis, 15 satisfaction variables were considered (see Table 3).

Table 3 Description of the variables included in the analysis with their variable name. Satisfaction variables are all on a 7-point Likert scale $(1=$ very satisfactory to $7=$ very unsatisfactory)

\begin{tabular}{|c|c|c|}
\hline & Variable description & Variable name \\
\hline \multirow{6}{*}{ Momentary } & Satisfaction with light at the desk & Light desk \\
\hline & $\begin{array}{l}\text { Satisfaction with natural light } \\
\text { (daylight) }\end{array}$ & Natural \\
\hline & $\begin{array}{l}\text { Satisfaction with artificial (electric } \\
\text { lighting) }\end{array}$ & Artificial \\
\hline & Satisfaction with glare from sunlight & Glare sun \\
\hline & $\begin{array}{l}\text { Satisfaction with glare from artificial } \\
\text { lighting }\end{array}$ & Glare artificial \\
\hline & Satisfaction with lighting quality & Lighting quality \\
\hline \multirow{9}{*}{ Annual } & Satisfaction with light at the desk & A-Light desk \\
\hline & $\begin{array}{l}\text { Satisfaction with natural light } \\
\text { (daylight) }\end{array}$ & A-Natural \\
\hline & $\begin{array}{l}\text { Satisfaction with artificial (electric } \\
\text { lighting) }\end{array}$ & A-Artificial \\
\hline & Satisfaction with glare from sunlight & A-Glare sun \\
\hline & $\begin{array}{l}\text { Satisfaction with glare from artificial } \\
\text { lighting }\end{array}$ & A-Glare artificial \\
\hline & Satisfaction with lighting quality & A-Lighting quality \\
\hline & Satisfaction with the view to outside & A-View \\
\hline & $\begin{array}{l}\text { Satisfaction with overall indoor } \\
\text { environmental quality (i.e. thermal, } \\
\text { acoustical) }\end{array}$ & A-IEQ \\
\hline & Satisfied with job & A-Job \\
\hline
\end{tabular}

\subsection{Hypothesis}

Step 5 of the EBD process is for 'developing a hypothesis', which can be used for further investigation of the value of interest (i.e., visual comfort). As illustrated in Fig. 1, the hypothesis is evaluated after a 'comparison' of the subjectiveobjective data. The two hypotheses developed in this study are as follows:

$1)$ Simple metrics such as the vertical eye illuminance $\left(E_{\mathrm{v} \text {-eye }}\right)$, horizontal task illuminance $\left(E_{\mathrm{h} \text {-task }}\right)$ and horizontal room illuminance $\left(E_{\text {h-room }}\right)$ have higher correlations than complex 
glare indices such as Daylight Glare Probability (DGP), Daylight Autonomy (DA), Spatial Daylight Autonomy (sDA) and Annual Sunlight Exposure (ASE) with instantaneous perceived occupant visual comfort. and

2) Human visual comfort perception for instantaneous situations (moment in time) and modeled comfort performance have a higher agreement than human perception for annual estimations and modeled performance.

\section{Results}

In this section, first, the results of the objective evaluation using light simulation are reported for 'illuminance-related visual comfort metrics' and 'glare-related visual comfort metrics' according to Table 1 . Then, descriptive statistics and intercorrelations of subjective evaluation using questionnaires are described, and finally, the correlation between objectivesubjective evaluation is analyzed.

\subsection{Objective evaluation using light simulation}

\subsubsection{Illuminance-related visual comfort metrics}

First, the simulation results were compared against a limited and random set of illuminance measurements in the real building. The results showed a difference between the simulated and real values of $20 \% \pm 11 \%$, which is within normal variability levels for simulated objects (Ochoa et al. 2012).

- Point-in-time horizontal illuminance for the entire room $\left(E_{\text {h-Room }}\right)$

Figure 4 shows examples of horizontal illuminance levels at the work plane height for rooms on both floors in a false color image for the same moment in time (clear sky condition, simulated date and time: October 11th, $10 \mathrm{AM}$ ). The size of the windows on the second floor is one-half larger than that on the third floor; therefore, the average illuminance values from daylight for the second floor (mean value of the sensor points $M=129 \pm 47$ lux) are 2.7 times higher than those for the third floor. On the second floor, only one room on the south-west side is analyzed, which is located on the southernmost side of the floor. This room is larger than the other rooms and has two windows. The results show that the light levels on the south-west side (mean value of the sensor points $M=$ $138 \pm 27$ lux) of the building are higher (3.45 times) than those on the north-east side ( $M=40 \pm 26$ lux), with the exception of one room on the southernmost side of the floor, which has higher light levels since the shading from the surrounding building does not have much of an effect.

- Point-in-time horizontal illuminance for the task/ workplace $\left(E_{\mathrm{h} \text {-task }}\right)$

The mean, maximum and minimum horizontal illuminance at the desk area under three different sky conditions were calculated. Figure 5 shows the simulation results for a top view of multiple rooms and a zoomed-in perspective view for one workplace (under a clear sky condition).

The mean illuminance values ( $E_{\text {h-task }}$ ) for all rooms included in the study, under three different sky conditions, are illustrated in Fig. 6. Note that the rooms labeled as S1 on both floors are on the southernmost side of the building, and the shading from a surrounding building does not have much of an effect.

- Vertical eye illuminance $\left(E_{\mathrm{v} \text {-eye }}\right)$

The vertical eye illuminance $\left(E_{\mathrm{v}-\text { eye }}\right)$ at the center point of each room was calculated under three different sky conditions, and the results are illustrated in Fig. 7. The viewing direction was always toward the daylight opening. The results show that on days with the clear sky condition, the $E_{\text {veye }}$ levels were near or more than 200 lux for most of the rooms, whereas on overcast days, these levels only occasionally exceeded 100 lux.
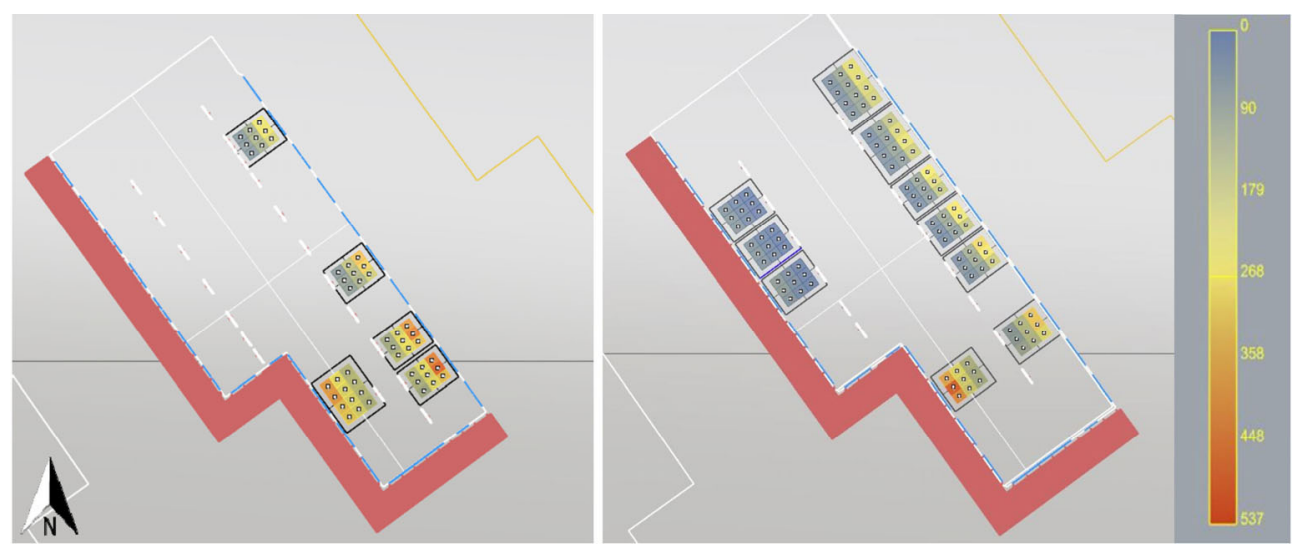

Fig. 4 Simulation results showing horizontal illuminance values (lux) at room area with work plane height under the clear sky condition (simulated date and time: October 11th, 10AM) second floor (left) and third floor (right) 

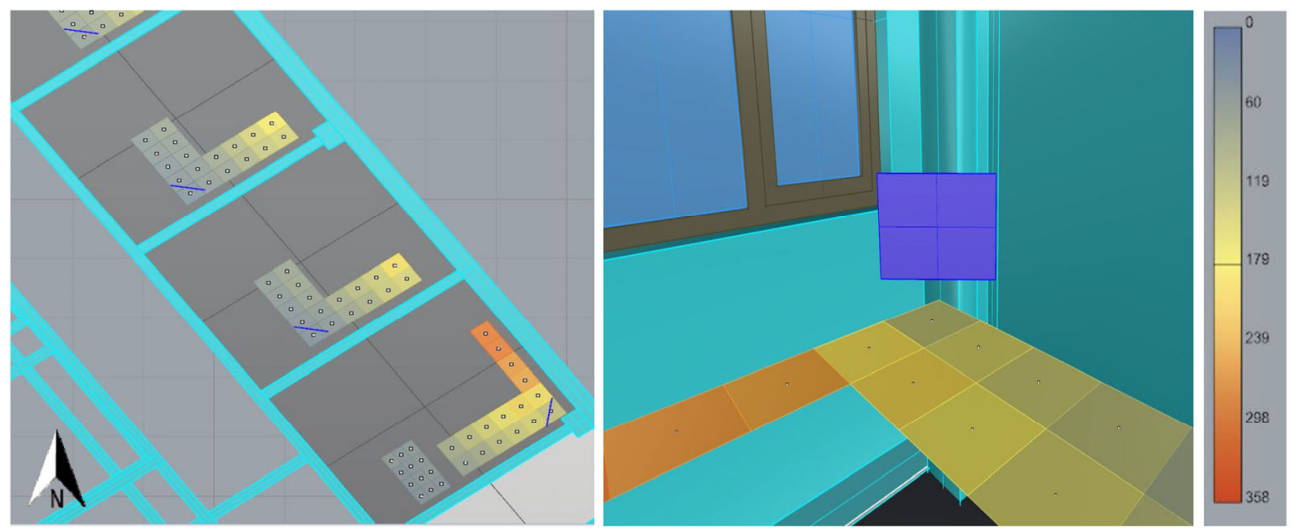

Fig. 5 Simulation results showing horizontal illuminance values (lux) at task area at work plane height under the clear sky condition from a top view for multiple offices L3N2-N4 (left) and perspective view for workplace L3N2 (right)

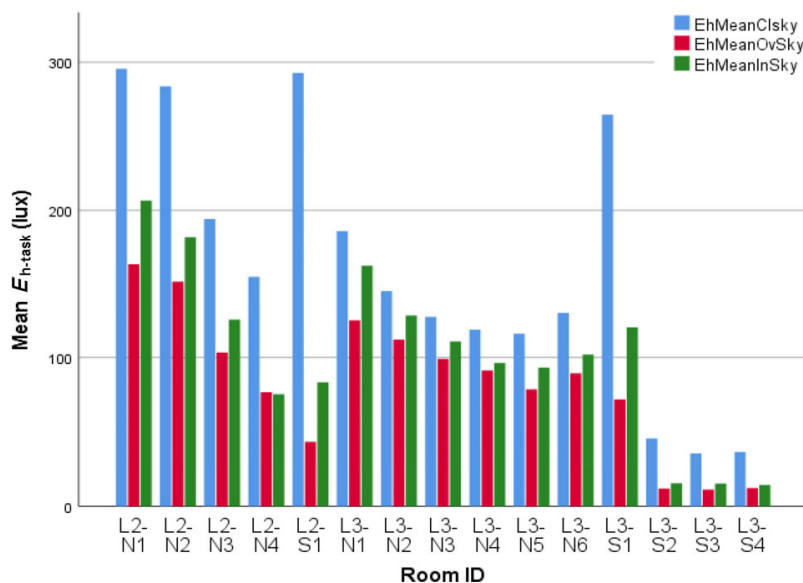

Fig. 6 Mean horizontal illuminance values at desk area under clear sky (blue), overcast sky (red), and intermediates sky (green) conditions (room ID L2 and L3 represent second and third floors respectively where $\mathrm{N}$ and $\mathrm{S}$ represent the North-East and South-West locations respectively)

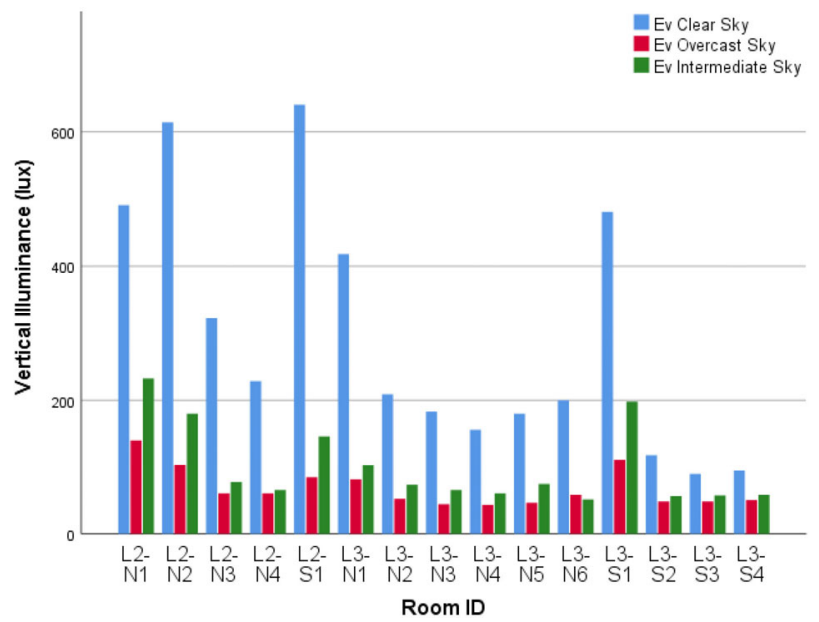

Fig. 7 Vertical illuminance values at desk area under clear sky (blue), overcast sky (red), and intermediates sky (green condition) condition (room ID L2 and L3 represent second and third floors respectively where $\mathrm{N}$ and $\mathrm{S}$ represent the North-East and SouthWest locations respectively)
- Daylight Autonomy (DA) and Spatial Daylight Autonomy (sDA)

DA was calculated for a whole year during working hours (8 AM to 6 PM) with a target illuminance of 300 lux. The highest value for the DA was found for the rooms on the second floor, with an average of $44 \% \pm 8 \%$. The rooms on the third floor on the north-east side had a DA value of approximately $29 \% \pm 3 \%$, and those on the south-west side had the lowest DA value of approximately $2 \% \pm 0.3 \%$. The sDA values of all rooms were lower than $50 \%$ of the space area.

\subsubsection{Glare-related visual comfort metrics}

- Daylight Glare Probability (DGP)

The center point of each room with a direction toward the windows was selected for DGP analysis. The results of this analysis show that for all rooms under the 'overcast' and 'intermediate' sky conditions, the DGP value is below the 'perceptible' level $(0.30<\mathrm{DGP}<0.35)$. The DGP values under the clear sky type for the rooms on the second floor and north-east side of the third floor (L3N) are in the range of intolerable glare (DGP > 0.45). The DGP values per room are presented in Fig. 8.

- Annual Sunlight Exposure (ASE)

For all rooms, the value of ASE was low. Less than 10\% of the rooms' areas had illuminance values higher than 1000 lux/250 hours per year, which means, according to the LEED certification, the rooms are categorized as rooms with not too much direct sunlight during the year (USGBC 2018).

\subsection{Subjective evaluation using questionnaires}

\subsubsection{Descriptive statistics}

Descriptive statistical calculations were performed on 15 questionnaire variables listed in Table 3 . All variables received a valid response from all participants $(N=15)$. In total, 


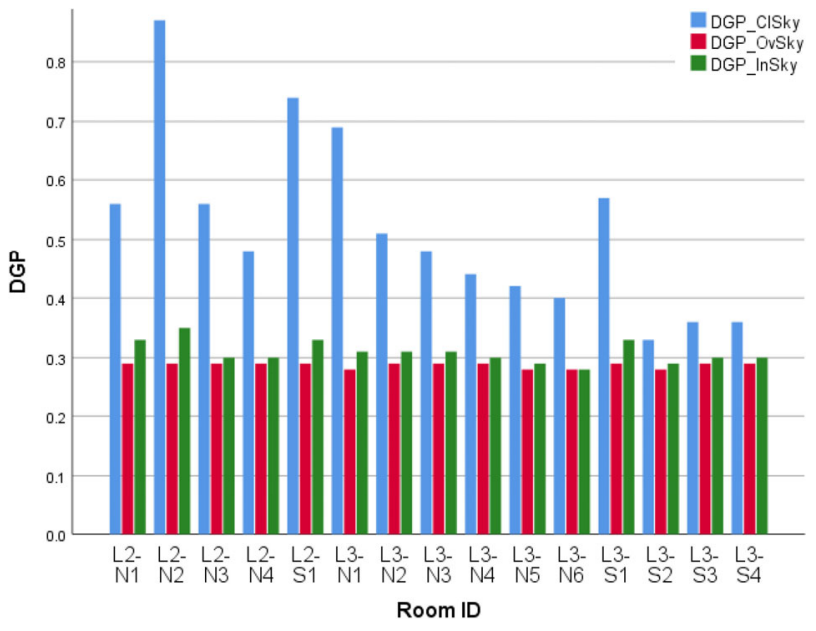

Fig. 8 DGP values under clear sky (blue), overcast sky (red), and intermediates sky (green condition) condition imperceptible level $(\mathrm{DGP}<0.3)$ perceptible $(0.3<\mathrm{DGP}<0.35)$, disturbing glare $(0.35<\mathrm{DGP}<0.4)$, intolerable glare $(\mathrm{DGP}>0.45)$ (room ID L2 and $\mathrm{L} 3$ represent second and third floors respectively where $\mathrm{N}$ and $\mathrm{S}$ represent the North-East and South-West locations respectively)

the mean value of satisfaction for all variables was between 2.33 and 3.73 (with 2 as being 'satisfied' and 3 as 'almost satisfied'). The highest satisfaction rate belonged to job satisfaction $(M=2.33, \mathrm{SD}=1.95)$, and after that, participants were most satisfied with the prevention of glare from the sun, which is reasonable because in October, the glare from the sun is not very high $(M=2.47, \mathrm{SD}=1.19)$. The lowest satisfaction ratings belonged to overall lighting quality $(M=$ $3.73, \mathrm{SD}=1.39)$ and daylight (moment) $(M=3.73, \mathrm{SD}=1.53)$. See Table 4 for an overview of all variables.

Table 4 Descriptive statistical calculations on 15 questionnaires' variables. Satisfaction variables are all on a 7-point Likert scale ( $1=$ very satisfactory to $7=$ very unsatisfactory)

\begin{tabular}{lc}
\hline \multicolumn{1}{c}{ Variable } & Mean \pm std. deviation \\
\hline A-light desk & $3.60 \pm 0.91$ \\
A-Natural & $3.27 \pm 1.33$ \\
A-Artificial & $3.67 \pm 1.11$ \\
A-Glare sun & $3.13 \pm 1.46$ \\
A-Glare artificial & $3.40 \pm 1.50$ \\
A-View & $3.67 \pm 2.35$ \\
A-Lighting quality & $3.73 \pm 1.39$ \\
A-IEQ & $3.33 \pm 1.11$ \\
A-Job & $2.33 \pm 1.95$ \\
Light desk & $3.67 \pm 1.11$ \\
Natural & $3.73 \pm 1.53$ \\
Artificial & $3.53 \pm 0.91$ \\
Glare sun & $2.47 \pm 1.19$ \\
Glare artificial & $3.13 \pm 1.51$ \\
Lighting quality & $3.53 \pm 1.19$ \\
\hline Valid $N$ (listwise) & 15 \\
\hline
\end{tabular}

\subsubsection{Intercorrelation analysis}

The intercorrelation of all fifteen satisfaction variables was explored by calculating Pearson correlation coefficients, and only significant correlations are reported here. The results showed that there were 'strong' $(0.6<p<0.79)$ to 'very strong' $(0.8<p<1)$ degrees of correlations for most of the variables between annual (i.e., 'A-glare artificial' variable) and momentary (i.e., 'glare artificial' variable) situations, including 'light desk', 'artificial', 'glare artificial', 'glare sun', and 'lighting quality'. The highest correlation was found between 'A-lighting quality' and 'lighting quality' $(r=0.92, N=15, p \leq 0.01)$. There was no clear correlation for daylight between moment-in-time and annual $(r=0.45, N=15, p \leq 0.01)$.

The variable 'A-lighting quality' showed a strong correlation with the 'A-light desk' variable $(r=0.76, N=15$, $p \leq 0.001)$. Both light sources seemed to contribute to the assessment of the 'lighting quality' in the room, with the correlation between 'A-artificial light' and 'A-lighting quality' ( $r=0.77, N=15, p \leq 0.001$ ) being just slightly higher than the correlation between 'A-natural light' and 'A-lighting quality' ( $r=0.66, N=15, p \leq 0.008$ ). 'A-lighting quality' also showed a strong correlation with annual perceived overall indoor environmental quality 'A-IEQ' $(r=0.76, N=15, p \leq$ 0.001 ), indicating that lighting defines an important part of the environmental quality assessment of space. Both the 'amount of artificial light (moment)' and 'amount of artificial light (annually)' showed strong correlations with the 'amount of light on desk area' ( $r=0.78, p \leq 0.001$ and $r=0.78, p \leq$ 0.001 , respectively, $N=15$ ). 'glare from artificial light' had a strong correlation with 'lighting-desk area' and the 'lighting quality at the moment' $(r=0.65, p \leq 0.009$ and $r=0.55, p \leq$ 0.33 , respectively, for $N=15$ ). Even though some people worked with daylight only or a combination of daylight and electric lighting and experienced situations where the amount of daylight at the desk was (much) higher than that of the electric lighting, the assessment of the light quality at the task area' seems to be linked to the 'amount and quality' of artificial lighting only.

\subsection{Subjective-objective correlation analysis}

Since a linear relationship was assumed between the simulation results and perceived user comfort, neither of the two variable types was manipulated, and both variables could be dependent and independent variables. Pearson correlation coefficients were calculated between simulation outcomes and questionnaire results. Correlations were investigated for the mean, maximum, and minimum values of the simulated variables to indicate whether an average or extreme situation would determine the user's perception. Only items that had a significant correlation are described. 
3.3.1 Correlation between performance metrics and perceived visual comfort (simple vs complex visual comfort metrics)

In total, five subjective variables including satisfaction with 'A-glare sun', 'daylight (both annual and moment)', 'A-view', and 'A-IEQ' had a significant correlation with at least one of the computer-simulated performance metrics.

The variable 'A-glare sun' was strongly correlated with point-in-time horizontal illuminance at the task area $\left(E_{\mathrm{h} \text {-task }}\right)$ for maximum values under the overcast sky condition $(r=$ $0.721, N=15, p \leq 0.002$ ).

Satisfaction with natural light (daylight) for both annual and momentary situations showed a high correlation with $E_{\mathrm{h} \text {-task. }}$ The correlation was significant between 'natural' and the mean value of $E_{\mathrm{h} \text {-task }}$ under the clear sky condition ( $r=$ $-0.53, N=15, p \leq 0.04)$ and the minimum value under the intermediate sky condition $(r=-0.54, N=15, p \leq 0.039)$. 'A-natural' was found to be correlated with both the mean and minimum values of $E_{\mathrm{h} \text {-task }}$ under the clear sky condition $(r=-0.54, N=15, p \leq 0.035)$ and $(r=-0.56, N=15, p \leq$ $0.03)$, respectively. 'A-natural' also had a high correlation with point-in-time horizontal illuminance at the room area $\left(E_{\mathrm{h} \text {-room }}\right)$ for the mean and minimum values of $E_{\mathrm{h} \text {-room. }}$. Another correlation was found between the perceived amount of natural light at the moment 'natural' and vertical illuminance $\left(E_{\mathrm{v}-\text { eye }}\right)$ under the overcast sky condition $(r=-0.53, N=15$, $p \leq 0.04)$.

Since the view to the outside often is inextricably linked to daylight, that variable was included as well, and 'view' had a significant correlation with the vertical illuminance $\left(E_{\mathrm{v} \text {-eye }}\right)$ and DGP, as well as with the horizontal illuminance at the task area $\left(E_{\mathrm{h} \text {-task }}\right)$ and room area $\left(E_{\mathrm{h} \text {-room }}\right)$ under 'clear' and 'intermediate' sky conditions.

'Overall indoor environment quality' had a significant correlation with the maximum values of $E_{\mathrm{h} \text {-task }}$ under the 'clear' sky condition $(r=-0.66, N=15, p \leq 0.01)$ and a significant moderate correlation with $E_{\mathrm{v} \text {-eye }}$ under all three sky conditions $(r=-0.55, N=15, p \leq 0.03)$.

\subsubsection{Annual human visual comfort perception versus annual lighting simulation metrics}

Performance metrics that covered the annual evaluation of daylight situations (ASE, DA, sDA and UDI) and related user feedback ('Annual' variables in Table 3, including A-light desk, A-natural, A-glare sun, A-view, and A-lighting quality) were correlated. Surprisingly, the only significant moderate correlation was found between 'glare from sun' and the mean DA $(r=0.53, p \leq 0.04, N=15)$.

\section{Discussion}

Translation between user evaluation and simulated evaluation of a lit environment is a critical and not (intensively) studied step in the integration of lighting simulation with EBD. Therefore, post-occupancy evaluation was chosen as the main subject in the current study. Using the EBD-SIM framework, currently often used performance metrics and a suitable questionnaire related to visual comfort were obtained (step 2. Finding sources for relevant evidence and step 3. Critically interpreting relevant evidence of the EBD process). Based on these indicators, subjective questionnaire data and objective simulated data were collected and compared.

To investigate how the most frequently used visual comfort metrics relate to perceived occupant visual comfort, the correlations between performance metrics and human perception were calculated by comparing illuminance values ( $\left.E_{\mathrm{v} \text {-eye, }}, E_{\mathrm{h} \text {-room }}, E_{\mathrm{h} \text {-task }}, \mathrm{DA}, \mathrm{sDA}\right)$ and glare indicators (DGP, ASE) against 15 variables obtained from the questionnaire. Even though the sample size of the performed POE was small $(N=15)$, certain trends are visible. The results show that although illuminance preference varies greatly among individuals, there was a positive significant correlation between overall lighting quality perceived by the occupants and the amount of light on the task area. Regarding performance metrics, the results show the highest correlation with point-in-time horizontal illuminance $\left(E_{\text {hor }}\right)$, especially on the task area $\left(E_{\mathrm{h} \text {-task }}\right)$, and human perception. These findings are in agreement with some other studies (i.e., Newsham et al. 2008), although there are studies (Van Den Wymelenberg and Inanici 2014; Bian and Luo 2017) that found that the vertical illuminance outperformed all commonly used visual comfort metrics. It should be noted that in this study, the calculation of $E_{\mathrm{h} \text {-task }}$ took into account how the occupant truly used the room. All other calculated metrics evaluated the rooms using a similar setting (e.g., the DGP was calculated for the center point of each room with a direction toward the windows) without consideration of the user's location/orientation and other user-specific parameters.

To summarize these results, it seems that point-in-time horizontal illuminance of the task and room areas had the highest correlation with human perception compared with other metrics. Additionally, $E_{\mathrm{v}}$ showed a good correlation. The results confirm the first hypothesis that simple metrics such as $E_{\text {h-task }}$ have a higher correlation with perceived visual comfort than complex performance metrics such as DA. Follow-up simulations may show whether this was just a coincidence or if a more detailed simulation of the actual/intended use of a space is required to forecast visual comfort.

To determine to what extent instantaneous and annual human visual comfort perceptions correlate with simulated comfort assessment, the human perception of light at a 
moment in time and for the annual situation were compared. There were 'high' to 'very high' correlations for some variables, e.g., artificial light, glare, and lighting quality; however, there was no significant correlation for daylight between moment-in-time and annual. Correlation analysis of annual performance metrics (ASE, DA, sDA and UDI) and related user feedback did not show significant correlations. It seems that the human perception of lit environments mainly depends on the instantaneous perception of the environment rather than average annual metrics; therefore, it is very important to conduct a survey during the most common light situation, or POEs should be conducted more frequently to obtain better insight into user perception of daylight and subsequently use new evidence to further improve the design of the EBD-SIM model.

Performance metrics such as Daylight Autonomy (DA) and Daylight Glare Probability (DGP) are valuable metrics to determine the basic lighting quantities and qualities in interior spaces and can help lighting designers and architects to improve their design solutions. However, regarding a POE, simple performance metrics show a higher correlation with user satisfaction, especially for satisfaction with the amount of light and glare as well as for IEQ and view. To further verify this finding, a reverse approach can be applied to predict user satisfaction given performance metrics suggested in this study.

One of the limitations of the current study was that the simulation results included only daylight, while some of the occupants worked under a combination of daylight and artificial light. Even though they were asked to answer about their perceptions of daylight, it may have been difficult for them to distinguish between these two light sources. Follow-up studies may show if it would be better that a simulation-based study covers both light sources.

Even though additional information related to the users was collected (i.e., age, gender, light sensitivity), this information was not used due to the limited sample size. Follow-up studies may show whether it is necessary to include additional input from users such as user characteristics, e.g., light sensitivity, user behavior or user preferences.

\section{Conclusion}

In this study, the application of the EBD-SIM framework was investigated by conducting a simple case study performed in an existing office building in Sweden to analyze visual comfort from subjective and objective points of view. The study indicated that using a systematic approach such as EBD for data gathering and evaluation of human responses during POE and integrating it with performance-based analysis, such as simulation-based assessment, can be used to extend the knowledge regarding the effects of the built environment on humans; however, several rounds of the EBD process are still required to find, for example, whether detailed inputs of the light sources, the expected users and their behavior or the intended use of a space is critical or crucial.

Simple metrics such as $E_{\mathrm{h} \text {-room }}$ and $E_{\mathrm{h} \text {-task }}$ had a higher correlation with perceived visual comfort than complex performance metrics such as DA. On the other hand, the results suggest that human perception of a lit environment mainly relies on the instantaneous perception of the environment; therefore, it is very important to conduct a survey during the most common light situation, or POEs should be conducted more frequently to obtain better insight into user perception of daylight and subsequently use new evidence to further improve the design of the EBD-SIM model.

\section{Appendices}

\section{A. Review of the criteria for objective assessment of visual comfort}

A simple state of the art literature review was conducted to find available visual comfort metrics. Literature extracted from the scientific database Scopus was studied. Scopus was chosen since it is the largest abstract and citation database of peer-reviewed literature and it provides access to science, technology, and medicine (STM) journal articles (Burnham 2006). Search results were narrowed to literature in the English language and covered materials produced until 2018/05/18. The terms "visual comfort metrics, index, and assessment" were used for the search. The search was performed based on the articles' title, keywords, and abstract.

The search strategy for finding visual comfort metrics, index, and assessment criteria in the office setting resulted in eleven articles. Ruck et al. (2000) identified four primary performance factors related to visual comfort: illuminance, glare, distribution, and direction. Due to its ease of use and low cost to measure, horizontal illuminance is the most widely applied metric (Van Den Wymelenberg 2013). Advances in computational power and computational daylight simulations allowed calculation of a wide array of dynamic climate-based daylighting metrics such as Daylight Autonomy (DA), spatial DA (sDA), Useful Daylight Illuminance (UDI), and continuous DA (conDA), as well as metrics related to glare analysis, including Daylight Glare Probability (DGP), daylight glare index (DGI), and Annual Sun Exposure (ASE), for analyzing comfort aspects (Nabil and Mardaljevic 2006; Reinhart et al. 2006; Wienold and Christoffersen 2006; Heschong et al. 2012). Three studies investigated the subjective-objective evaluation of visual comfort metrics. Bian and Luo (2017) analyzed the correlations 
Table 5 Overview of the literature results and the metrics they applied related to visual comfort

\begin{tabular}{lll}
\hline$\#$ & \multicolumn{1}{c}{ References } & \multicolumn{1}{c}{ Visual comfort metrics } \\
\hline 1 & Bian and Luo 2017 & Ev, DGI, DGP, luminance ratio and window/workplace luminance \\
2 & Cannavale et al. 2013 & UDI, DGP \\
3 & Cannavale et al. 2017 & UDI, DGP \\
4 & Chatzikonstantinou and Sariyildiz 2016 & DA, DGP \\
5 & Costanzo and Donn 2017 & sDA300, 50\% ASE1000, 250h \\
6 & Konis et al. 2011 & HDR, luminance map, DGI \\
7 & Linhart and Scartezzini 2011 & Illuminances/subjective assessment \\
8 & Motamed et al. 2017 & DGP, novel HDR vision sensor \\
9 & Vera et al. 2017 & sDA, ASE \\
10 & Van Den Wymelenberg and Inanici 2016 & Luminance-based, standard deviation of window luminance \\
11 & Van Den Wymelenberg and Inanici 2014 & Vertical illuminance, horizontal illuminance, IES luminance ratios, DGP, DGI \\
\hline
\end{tabular}

among vertical eye illuminance $\left(E_{\mathrm{v}}\right)$, daylight glare index (DGI), daylight glare probability (DGP), luminance ratio and window/work plane luminance. The results showed that simple luminance metrics (e.g., work plane luminance and vertical eye illuminance) outperformed complex glare indices (e.g., DGP/DGI and luminance ratio). In a daylit private office laboratory environment, Van Den Wymelenberg and Inanici (2014) evaluated and critiqued existing visual comfort metrics based on their ability to explain the variability in human subjective responses. Vertical illuminance outperformed all commonly referenced visual comfort metrics, including horizontal illuminance, IES luminance ratios, daylight glare probability (DGP), and daylight glare index (DGI). Later, Van Den Wymelenberg and Inanici (2016) proposed a new suite of visual comfort metrics and evaluated them for their ability to explain the variability in subjective human response. They argued that luminancebased metrics were more capable than illuminance-based metrics in predicting a user's visual preference. Luminance maps indicated that more detailed spatial analysis was needed when assessing the visual comfort performance of innovative facade systems (Konis et al. 2011). One study (Chatzikonstantinou and Sariyildiz 2016) experimented with using machine learning techniques on data from simulation results of visual comfort analysis of office spaces. Three machine learning methods were compared with respect to applicability in approximating daylight autonomy and daylight glare probability. Their comparison focused on the accuracy and time cost of training and estimation. The estimation time was nearly instant, and the accuracy was sufficient for use in the conceptual design phase. The remaining studies used common visual comfort metrics for the assessment of visual comfort. An overview of the metrics per article is shown in Table 5. As the results show, the most frequently used performance metrics in this field are dynamic climate-based daylighting metrics, illuminance and luminance-based metrics and DGP for glare analysis.
B. Review of the questionnaire for subjective assessment of visual comfort

To find relevant questionnaire items in this field, a snowball sampling method (Goodman 1961) was conducted starting with two articles (Veitch et al. 2007; Dykes and Baird 2013) known to have applied visual comfort questionnaires in an office environment. In general, two types of questionnaires were found. Some were about indoor environment quality focusing on office buildings, where one of the aspects was lighting quality (Dillon and Vischer 1987; Stokols and Scharf 1990; Carlopio 1996; Veitch et al. 2007; Bluyssen et al. 2011; Peretti and Schiavon 2011; Dykes and Baird 2013). There were also surveys on lighting, especially visual comfort and satisfaction within all types of buildings (Hygge and Lofberg 1997; Velds and Christofferesen 2001; Konis 2013). Both types of questionnaires were considered in this study.

\section{Acknowledgements}

The authors would like to acknowledge the financial support of the Region Jönköpings Län's FoU-fond Fastigheter and the Bertil and Britt Svenssons Stiftelse för Belysningsteknik. Also, we would like to acknowledge the valuable comments by the reviewers of the journal of Building Simulation and Professor Christine Räisänen for proofreading the manuscript.

Funding note: Open access funding provided by Jönköping University.

Open Access: This article is licensed under a Creative Commons Attribution 4.0 International License, which permits use, sharing, adaptation, distribution and reproduction in any medium or format, as long as you give appropriate credit to the original author(s) and the source, provide a link to the Creative Commons licence, and indicate if changes were made. 
The images or other third party material in this article are included in the article's Creative Commons licence, unless indicated otherwise in a credit line to the material. If material is not included in the article's Creative Commons licence and your intended use is not permitted by statutory regulation or exceeds the permitted use, you will need to obtain permission directly from the copyright holder.

To view a copy of this licence, visit http://creativecommons.org/licenses/by/4.0/.

\section{References}

Bian Y, Luo T (2017). Investigation of visual comfort metrics from subjective responses in China: A study in offices with daylight. Building and Environment, 123: 661-671.

Bluyssen PM, Aries M, van Dommelen P (2011). Comfort of workers in office buildings: The European HOPE project. Building and Environment, 46: 280-288.

Burnham JF (2006). Scopus database: a review. Biomedical Digital Libraries, 3: 1.

Cannavale A, Fiorito F, Resta D, Gigli G (2013). Visual comfort assessment of smart photovoltachromic windows. Energy and Buildings, 65: 137-145.

Cannavale A, Hörantner M, Eperon GE, Snaith HJ, Fiorito F, Ayr U, Martellotta F (2017). Building integration of semitransparent perovskite-based solar cells: Energy performance and visual comfort assessment. Applied Energy, 194: 94-107.

Carlopio JR (1996). Construct validity of a physical work environment satisfaction questionnaire. Journal of Occupational Health Psychology, 1: 330-344.

Carlucci S, Causone F, de Rosa F, Pagliano L (2015). A review of indices for assessing visual comfort with a view to their use in optimization processes to support building integrated design. Renewable and Sustainable Energy Reviews, 47: 1016-1033.

Chatzikonstantinou I, Sariyildiz S (2016). Approximation of simulationderived visual comfort indicators in office spaces: a comparative study in machine learning. Architectural Science Review, 59: 307-322.

Costanzo V, Donn M (2017). Thermal and visual comfort assessment of natural ventilated office buildings in Europe and North America. Energy and Buildings, 140: 210-223.

Cuttle C (2015). Lighting Design: A Perception-Based Approach. Abingdon, UK: Routledge.

Davoodi A (2016). Lighting simulation for a more value-driven building design process. Licentiate Thesis, Lund University, Sweden.

Davoodi A, Johansson P, Henricson M, Aries M (2017). A conceptual framework for integration of evidence-based design with lighting simulation tools. Buildings, 7: 82.

Dillon R, Vischer JC (1987). Derivation of the Tenant Questionnaire Survey assessment method: Office building occupant survey data analysis, Public works Canada.

Dykes C, Baird G (2013). A review of questionnaire-based methods used for assessing and benchmarking indoor environmental quality. Intelligent Buildings International, 5: 135-149.
Goodman LA (1961). Snowball sampling. The Annals of Mathematical Statistics, 32: 148-170.

Heschong L, Wymelenberg VD, Andersen M, Digert N, Fernandes L, Keller A, Loveland J, McKay H, Mistrick R, Mosher B (2012). IES LM-83-12. Approved Method: IES Spatial Daylight Autonomy (sDA) and Annual Sunlight Exposure (ASE), IES-Illuminating Engineering Society.

Hien WN, Poh LK, Feriadi H (2000). The use of performance-based simulation tools for building design and evaluation-a Singapore perspective. Building and Environment, 35: 709-736.

Hygge S, Lofberg H (1997). User evaluation of visual comfort in some buildings of the Daylight Europe Project. In: Proceedings of Right Light Four, the fourth European conference on Energy-Efficient Lighting, Copenhagen, Denmark, vol. 2, pp. 69-74.

Jakubiec JA, Reinhart CF (2011). DIVA 2.0: integrating daylight and thermal simulations using Rhinoceros 3D, Daysim and Energyplus. In: Proceedings of the 12th International IBPSA Building Simulation Conference, Sydney, Australia.

Jakubiec JA, Reinhart CF (2012). The "adaptive zone"-A concept for assessing discomfort glare throughout daylit spaces. Lighting Research \& Technology, 44: 149-170.

Jakubiec JA, Reinhart CF, Van Den Wymelenberg K (2015). Towards an integrated framework for predicting visual comfort conditions from luminance-based metrics in perimeter daylit spaces. In: Proceedings of the 14th International IBPSA Building Simulation Conference, Hyderabad, India.

Kent MG, Fotios S, Altomonte S (2019a). An experimental study on the effect of visual tasks on discomfort due to peripheral glare. Leukos, 15: 17-28.

Kent MG, Fotios S, Altomonte S (2019b). Discomfort glare evaluation: The influence of anchor bias in luminance adjustments. Lighting Research \& Technology, 51: 131-146.

Konis K, Lee E, Clear R (2011). Visual comfort analysis of innovative interior and exterior shading systems for commercial buildings using high resolution luminance images. Leukos, 7: 167-188.

Konis K (2013). Evaluating daylighting effectiveness and occupant visual comfort in a side-lit open-plan office building in San Francisco, California. Building and Environment, 59: 662-677.

Linhart F, Scartezzini J-L (2011). Evening office lighting-Visual comfort vs. energy efficiency vs. performance? Building and Environment, 46: 981-989.

Malone E, Harmsen C, Reno K, Edelstein E, Hamilton D, Salvatore A (2008). An introduction to evidence based design: Exploring healthcare and design. Concord, CA: The Center for Health Design.

Michael A, Heracleous C (2017). Assessment of natural lighting performance and visual comfort of educational architecture in Southern Europe: The case of typical educational school premises in Cyprus. Energy and Buildings, 140: 443-457.

Michael A, Gregoriou S, Kalogirou SA (2018). Environmental assessment of an integrated adaptive system for the improvement of indoor visual comfort of existing buildings. Renewable Energy, 115: 620-633.

Motamed A, Deschamps L Scartezzini J-L (2017). On-site monitoring and subjective comfort assessment of a sun shadings and electric lighting controller based on novel High Dynamic Range vision sensors. Energy and Buildings, 149: 58-72. 
Nabil A, Mardaljevic J (2006). Useful daylight illuminances: A replacement for daylight factors. Energy and Buildings, 38: 905-913.

Newsham GR, Aries MBC, Mancini S, Faye G (2008). Individual control of electric lighting in a daylit space. Lighting Research \& Technology, 40: 25-41.

Ochoa CE, Aries MBC, Hensen JLM (2012). State of the art in lighting simulation for building science: A literature review. Journal of Building Performance Simulation, 5: 209-233.

Peretti C, Schiavon S (2011). Indoor environmental quality surveys. A brief literature review. In: Proceedings of the 12th International Conference on Indoor Air Quality and Climate, Austion, USA.

Reinhart C, Fitz A (2006). Findings from a survey on the current use of daylight simulations in building design. Energy and Buildings, 38: 824-835.

Reinhart CF, Mardaljevic J, Rogers Z (2006). Dynamic daylight perormance metrics for sustainable building design. Leukos, 3: 1-25.

Ruck N, Aschehoug O, Aydinli S, Christoffersen J, Edmonds I, Jakobiak R, Kischkoweit-Lopin M, Klinger M, Lee E, Courret G (2000). Daylight in buildings - A source book on daylighting systems and components. Lawrence Berkeley National Laboratory, Berkeley, USA.

Stokols D, Scharf T (1990). Developing standardized tools for assessing employees' ratings of facility performance. In: Davis G, Ventre F (eds), Performance of buildings and serviceability of facilities. Philadelphia, PA, USA: American Society for Testing and Materials.

USGBC (2008). LEED BD+C: New Construction | v4 - LEED v4: Daylight. Available at https://www.usgbc.org/credits/new-constructioncommercial-interiors-schools-new-construction-retail-newconstruction-ret-1. Accessed 27 Jan 2019.

Van Den Wymelenberg KG (2013). Evaluating human visual preference and performance in an office environment using luminance-based metrics. PhD Thesis, University of Washington, USA.
Van Den Wymelenberg K, Inanici M (2014). A critical investigation of common lighting design metrics for predicting human visual comfort in offices with daylight. Leukos, 10: 145-164.

Van Den Wymelenberg K, Inanici M (2016). Evaluating a new suite of luminance-based design metrics for predicting human visual comfort in offices with daylight. Leukos, 12: 113-138.

Vassiliades C, Michael A, Savvides A, Kalogirou S (2018). Improvement of passive behaviour of existing buildings through the integration of active solar energy systems. Energy, 163: 1178-1192.

Veitch JA, Charles KE, Farley KMJ, Newsham GR (2007). A model of satisfaction with open-plan office conditions: COPE field findings. Journal of Environmental Psychology, 27: 177-189.

Velds M, Christofferesen J (2001). Monitoring procedures for the assessment of daylighting performance of buildings. IEA SHC Task 21 "Daylight in Buildings"/ECBCS Annex 29. International Energy Agency.

Vera S, Uribe D, Bustamante W, Molina G (2017). Optimization of a fixed exterior complex fenestration system considering visual comfort and energy performance criteria. Building and Environment, 113: $163-174$.

Vischer JC (2009). Applying knowledge on building performance: From evidence to intelligence. Intelligent Buildings International, 1: 239-248.

Vischer JC, Zeisel J (2008). Bridging the gap between research and design. World Health Design, 2008(July): 57-61.

Wienold J, Christoffersen J (2006). Evaluation methods and development of a new glare prediction model for daylight environments with the use of CCD cameras. Energy and Buildings, 38: 743-757. 